\title{
A Critical Analysis of Climatic Influences on Indoor Radon Concentrations: Implications for Seasonal Correction
}

\author{
Groves-Kirkby, C. J., Crockett, R. G. M., Denman, A. R. \& Phillips, P. S.
}

\begin{abstract}
Although statistically-derived national Seasonal Correction Factors (SCFs) are conventionally used to convert sub-year radon concentration measurements to an annual mean, it has recently been suggested that external temperature could be used to derive local SCFs for short-term domestic measurements. To validate this approach, hitherto unanalysed radon and temperature data from an environmentally-stable location were analysed. Radon concentration and internal temperature were measured over periods totalling 1,025 days during an overall period of 1,762 days, the greatest continuous sampling period being 334 days, with corresponding meteorological data collected at a weather station $10 \mathrm{~km}$ distant. Mean daily, monthly and annual radon concentrations and internal temperatures were calculated.

SCFs derived using monthly mean radon concentration, external temperature and internal-external temperature-difference were cross-correlated with each other and with published UK domestic SCF sets. Relatively good correlation exists between SCFs derived from radon concentration and internal-external temperature difference; correlation with external temperature, implicit in the PHE formula, was markedly poorer. SCFs derived from external temperature correlate very well with published SCF tabulations, confirming that the complexity of deriving SCFs from temperature data may be outweighed by the convenience of using either of the existing domestic SCF tabulations.

Mean monthly radon data fitted to a 12-month sinusoid showed reasonable correlation with many of the annual climatic parameter profiles, exceptions being atmospheric pressure, rainfall and internal temperature. Introducing an additional 6-month sinusoid enhanced correlation with these three parameters, the other correlations remaining essentially unchanged. Radon latency of the order of months in moisture-related parameters suggests that the principal driver for radon is total atmospheric moisture content rather than relative humidity.
\end{abstract}




\section{A Critical Analysis of Climatic Influences on Indoor Radon Concentrations: Implications for Seasonal Correction}

\section{Introduction}

\subsection{Environmental Radon Gas and Public Health}

Radon, ${ }^{222} \mathrm{Rn}$, a naturally occurring radioactive gaseous decay product of radium $\left({ }^{226} \mathrm{Ra}\right.$, itself a decay product of uranium), is widely distributed in the geological environment in a variety of rocks and soils, and in building materials incorporating or manufactured from these. Ionising radiation is well known to have adverse health effects, and inhalation of radon gas and its solid progeny ${ }^{218} \mathrm{Po}$ and ${ }^{214} \mathrm{Po}$, both readily adsorbed onto atmospheric particulates, provides the majority of the radiation dose to the human respiratory system, leading to chemical and radiological damage to the sensitive inner lining of the lung, thereby increasing the risk of lung-cancer. This risk increases with cumulative long-term radon exposure, a convenient quantification being the estimated annual average radon level in a building. If a measurement is made over a shorter time period, then a seasonal correction is appropriate to estimate the annual average. In Europe, mortality from exposure to radon in buildings is estimated (Darby et al., 2004) to represent $9 \%$ of all deaths from lung-cancer and $2 \%$ of all cancer deaths. Total annual lung-cancer mortality in 2006 in the United Kingdom (UK) was 34,150, around 1,110 (3.3\%) being attributed to residential exposure to radon and its progeny (AGIR, 2009; Gray et al., 2009). These figures were little changed in 2010, with 1,376 radon-attributable deaths from lung cancer (3.4\% of the total) (Parkin and Darby, 2011).

Radon protection in England and the Devolved Administrations (Scotland, Wales and Northern Ireland) within the UK, formerly administered by the National Radiological Protection Board (NRPB), is currently the responsibility of the Centre for Radiation, Chemical and Environmental Hazards (CRCE), lately part of the UK Health Protection Agency (HPA) and now a division of Public Health England (PHE). Responding to the health threat posed by domestic radon in the UK, the NRPB initially established a residential Action Level of $200 \mathrm{~Bq}^{\cdot} \mathrm{m}^{-3}$ (O'Riordan, 1990), declaring as radon Affected Areas those geographical entities where over 1\% of measurements in the existing housing stock showed radon concentrations above the Action Level. While the growing number of available radon measurements from domestic properties, and the development of enhanced geological mapping techniques, has enabled potential Affected Areas to be indicated more precisely (Denman et al., 2013), there is still much to learn about radon and geology, especially as uranium and radon can, under the right hydrogeological circumstances, be transported for considerable distances. Geological evidence can therefore only ever be indicative, rather than diagnostic, of an indoor radon problem, and definition of a single SCF for the UK, which exhibits some of the most varied geology spatially in the world, is consequently extremely problematic.

\subsection{Radon and Climate}

Previous attempts to relate indoor radon concentration level and climate have proved inconclusive. While Postendörfer et al. (1994) concluded that, in a building with relatively stable air temperature, wind-speed was the principal factor determining indoor radon concentrations, an extended study (3,000 daily samples in three near-continuous groups) (Kobayashi, 2000) failed to identify such a correlation, although the power-spectrum of the radon progeny ratio was shown to be similar to that of wind-speed. Miles (2001) demonstrated good correlation between mean radon concentration and monthly temperature, but only while outdoor temperature is lower than that indoors, as required by the indoor under-pressure model (Eaton and Scott, 1984). Climent et al. (1999) showed radon concentration correlating inversely with air temperature and soil temperature at $300 \mathrm{~mm}$ soil depth, and directly with humidity, rainfall and wind direction, in each case with minimal latency. No correlation was evident with soil temperature at $100 \mathrm{~mm}$ depth, with wind speed or with seismic activity within a $100 \mathrm{~km}$ range. Dolejs and Hulka (2003), investigating the effect of climate on the 
difference between short- and long-term radon outcomes, showed that while atmospheric pressure and rainfall were not significant, external weekly mean temperature was a significant factor. Investigations into the effect of climate on radon concentration in three undisturbed domestic basement rooms in Northamptonshire failed to demonstrate rigorous causality, although weak correlations with precipitation and mean daily temperature were identified (Groves-Kirkby et al., 2006). Florea and Duliu (2012), reporting eighteen years of continuous observation of atmospheric radon, identified negative correlation between radon concentration and precipitation, temperature and sky cloudiness. Wavelet and power spectra confirmed the predominance of one year periodicity, with additional components with periodicity of 1.2, 1.5, 2.8 and 7.2 years. Finally, Perrier et al. $(2009,2013)$ have demonstrated the sensitivity of soil-gas radon flux and concentration to atmospheric pressure changes, in particular to periodic signals such as the semi-diurnal barometric tide S2 (Simpson, 1919), the response being dependent on the presence or absence of an interface, such as that between bed-rock and surface drift strata, and on the presence or absence of air and water.

\subsection{Seasonal Variability of Domestic Radon}

Soil-gas radon flux at a particular location is primarily determined by the location and quantity of its precursor radionuclides, while its subsequent migration and advection into buildings depends on the underlying rock and its fragmentation, soil stratification and water content. Soil characteristics are influenced by changes in meteorological conditions, many of which exhibit periodic, often annual, variability; temporal variations of soil-gas radon concentration are consequently widely observed (Neznal et al., 2004; Perrier and Girault, 2013). Since geomorphology varies from location to location, significant spatial variability of soil-gas radon can exist over an area of apparently stable soil geochemistry (Neznal et al., 1996).

Soil-gas radon can enter a building through any opening (cracks in solid floors, gaps in suspended floors, apertures around service entry points) in contact with the ground. In climates where homes are heated for at least part of the year, indoor air is generally warmer and less dense than outdoor air. The consequent pressure differential, the prime driving force for entry of soil-gas and its entrained radon, is modulated by the Bernoulli effect influence of wind passing around and over the building, with wind-speed contributing significantly in determining radon ingress (Eaton and Scott, 1984).

Phenomenologically, indoor domestic radon concentration levels are generally higher at night than during the day and generally higher in winter than in summer. These variations reflect reduced domestic activity at night, increased interior/exterior temperature difference at night and during the heating season and, where soil-gas advection forms the predominant radon source, the underlying climatically-defined seasonal variability in soil-gas radon content. In addition to the natural daily cycle, longer periodicities are evident, related to other causes. These include: external temperature (Karpinska et al., 2004; Miles, 2001); barometric pressure and wind direction (Miles, 2001); rainfall (Mose et al., 1991); occupancy patterns (Paridaens et al., 2005); seismic events (Crockett et al., 2006a); tidal effects, including barometric tides (Perrier and Girault, 2013) and ocean tidal-loading and earth-tides (Crockett et al., 2006b; Groves-Kirkby et al., 2006); the underlying geology (Gillmore et al., 2005; Miles and Appleton, 2005).

\subsection{Seasonal Correction Factors}

To compensate for seasonality when assessing radon risks, short-term measurement outcomes are generally converted to equivalent mean annual levels by application of a Seasonal Correction Factor (SCF). In the UK and elsewhere, this is a set of multiplying factors, generally (multi-) monthly by calendar month and national scope, applied to a medium-term radon concentration measurement, the current recommendation being 3 months (AGIR, 2009), to derive a meaningful annual average radon concentration, the standard quantifier of long-term health risk. SCF calculation requires 
knowledge of the measurement start-date and duration, and assumes annually-periodic, typically sinusoidal, variation (Pinel et al., 1995).

Initial concern as to the applicability of a single SCF set was raised by Pinel et al. (1995), who argued that, due to the UK's extensive geological variability, domestic SCFs derived from earlier nationwide study (Wrixon et al., 1988) might not be applicable in areas such as south-west England, which differs geologically to much of the remainder of the country. Subsequent study of radon levels in a set of homes situated on radon-rich Jurassic strata in Northamptonshire, England (Denman et al., 2007a) confirmed that the UK domestic SCF set was, indeed, not replicated by the experimental data. Using published data, Groves-Kirkby et al. (2009a, 2009b) showed that the set of domestic SCFs recommended for use across the UK (Wrixon et al., 1988; Miles and Howarth, 2008) differs significantly in both amplitude and phase from national SCF sets derived elsewhere in Europe (Azimi, 1996; Baysson et al., 2003; Bossew and Lettner, 2007; Burke and Murphy, 2011; Grainger et al., 2000; Hubbard and Hagberg, 1996; Karpinska et al., 2004; Tapia et al., 2006), in Asia (Singh et al., 2008) and in North America (Chen, 2001; Krewski et al., 2005).

UK seasonal variability has recently been reassessed (Miles et al., 2012, 2014), taking into account developments in understanding since the original analysis, and calculating from geometric mean rather than arithmetic mean radon concentrations to reflect the lognormal distribution of the underlying set of radon measurements. The resulting revised domestic SCF set implies somewhat lower seasonal variability than hitherto assumed.

\subsection{Seasonal Variability and Ambient Temperature}

Given the foregoing evidence, attention has been directed towards quantitative understanding of the underlying factors driving soil-gas radon emanation and ingress. Gunby et al. (1993) demonstrated that many of the physical and constructional characteristics of a house are potentially capable of affecting radon concentration levels and are realistic surrogates for indoor-outdoor pressure difference, and many of these originally identified associations have subsequently been confirmed (Miles et al., 2012). Miles $(1998,2001)$ argued that this pressure difference, itself a function of the indoor-outdoor temperature difference, is ultimately responsible for the seasonal variation in radon concentration, using the results of the original UK radon survey (Wrixon et al., 1988) to show that the mean monthly domestic radon concentration, $R$ (in units of $\mathrm{Bq} \cdot \mathrm{m}^{-3}$ ), was a simple linear function of the mean external temperature, $T$ (degrees Celsius), having the form:

$$
R=33-1.26 T
$$

This relationship applies only while average outdoor temperatures are lower than those indoors (and $\mathrm{T} \leq 26.2{ }^{\circ} \mathrm{C}$ ), the necessary condition for the classical driving mechanisms (Åkerblom et al., 1984; Eaton and Scott, 1984). Developing this approach, Ibrahimi and Miles (2009a, 2009b) presented a more general formula relating the mean annual radon concentration, $R$, in a dwelling to the occupancy-weighted mean radon concentration, $C$, observed in that dwelling during a relatively short measurement period, and the mean external temperature, $T$, during the same period:

$$
R=(C-4) \times(1 /[1.645-0.063 T])+4
$$

with units as previously. Since the mean UK outdoor radon concentration of $4 \mathrm{~Bq} \cdot \mathrm{m}^{-3}$ (Wrixon et al., 1988) is, to first order, unaffected by temperature, this component is subtracted from the measured concentration prior to applying the correction, and subsequently added back. Use of Equation (2) is now suggested for cases where a short measurement period, rather than the conventional three months, is imperative (Ibrahimi and Miles, 2009a, 2009b). 
The present study tests the validity of this approach by exploring a hitherto unanalysed dataset, gathered during a period extending over several years, although not entirely continuous, from an environment in which many of the anthropomorphic influences commonly affecting radon data collection have been minimised or excluded.

\section{Method}

\subsection{The Test Room}

During the period June 2003 to March 2008, a calibrated Durridge* RAD7 radon measuring system was deployed for extended periods in a rarely-visited partially-subterranean store-room (the Test Room) in a public institution in the town of Northampton, UK. This room forms part of the lowest level of a late $18^{\text {th }}$ century four-storey brick/stone building on a sloping site, measures approximately $2 \times 4 \times 3$ metres high and is bounded on its two longer sides by similar rooms. One shorter wall contains a door to the central corridor of the basement, while the other forms the windowless exterior wall of the building, beyond which is a small paved court-yard, with external ground level around 1 metre above the floor level in the room. The floor is tile/vinyl, on concrete of uncertain age and constitution, probably laid, given the age of the building, directly on the subsoil. Access was restricted and normally limited to one or two brief visit(s) per week by authorised personnel, generally at the same time of day on the same weekday and totalling at most $0.5 \%$ of the total investigation period. For the duration of the study, no changes were made to the room configuration and the door remained locked while the room was unattended.

\subsection{Radon Concentration Data}

Measurements of radon concentration and ambient temperature were made at hourly intervals, during the periods indicated in Table 1, gaps in the record corresponding to periods where the equipment was deployed elsewhere. Within the overall investigation period of 42,285 hours (1,761.8 days), monitoring equipment was running for 24,592 hours $(1,024.7$ days $), 58.2 \%$ of the total period. The maximum continuous run length was 8,026 hours ( 334.4 days), $19.0 \%$ of the total period, while the maximum non-measuring interval was 6,507 hours (271.1 days), $15.4 \%$ of the total period.

\footnotetext{
* Durridge Company, Inc. 524 Boston Road, Billerica, MA 01821-2812, USA
} 
Table 1: RAD7 data sampling periods

\begin{tabular}{ccccc}
\hline \hline \multicolumn{2}{c}{ Start (first record) } & \multicolumn{2}{c}{ Finish (end time) } & Series Count \\
\hline Date & Time & Date & Time & \\
\hline 04-Jun-03 & $16: 25$ & 28-Jul-03 & $15: 25$ & 1,296 \\
07-Apr-04 & $12: 30$ & 18-May-04 & $17: 30$ & 990 \\
22-May-04 & $21: 16$ & 28-May-04 & $12: 16$ & 136 \\
02-Jun-04 & $10: 11$ & 07-Jun-04 & $02: 11$ & 113 \\
25-Aug-04 & $11: 28$ & 27-Aug-04 & $10: 28$ & 48 \\
20-Sep-04 & $14: 26$ & 21-Sep-04 & $13: 26$ & 24 \\
27-Sep-04 & $11: 34$ & 14-Jun-05 & $16: 34$ & 6,246 \\
21-Jun-05 & $10: 30$ & 21-May-06 & $19: 30$ & 8,026 \\
23-May-06 & $15: 12$ & 26-Feb-07 & $12: 12$ & 6,694 \\
04-Apr-07 & $14: 17$ & 13-Apr-07 & $12: 17$ & 215 \\
16-May-07 & $11: 20$ & 25-May-07 & $12: 20$ & 218 \\
20-Feb-08 & $15: 02$ & 03-Mar-08 & $05: 02$ & 279 \\
18-Mar-08 & $18: 06$ & 31-Mar-08 & $12: 06$ & 307 \\
\hline Total Counts & \multicolumn{5}{c}{} & 24,592 \\
\hline \hline
\end{tabular}

\subsection{External Climate Data}

Daily average air temperature, atmospheric pressure, relative humidity, precipitation and windspeed data over the radon measurement period were downloaded retrospectively from the public web-site of Pitsford Hall Weather Station ${ }^{\dagger}$. This fully-equipped weather station, maintained by the Department of Geography, Pitsford School, and compliant with UK Meteorological Office standards for operation and instrumentation (COL Station No. 91012), is situated in open country $10 \mathrm{~km}$ north of the Test Room.

\section{Results}

\subsection{Radon Time Series}

Figure 1 presents the radon concentration time-series from the Test Room over the full investigation period, showing the measurement periods and the intervening non-measuring intervals. Radon concentrations predominantly lie in the region below $150 \mathrm{~Bq} \cdot \mathrm{m}^{-3}$ throughout the observation period, with a number of transient excursions exceeding $400 \mathrm{~Bq} \cdot \mathrm{m}^{-3}$. Various techniques exist for imputation of missing time-series data in the computation of individual cumulative radon dose, among them consideration of fully-populated time-series only, replacing blank data points with one of a number of differently-derived series average values, and elimination of zero-valued intervals from the calculation (Weinberg et al., 1996). Since the present study is not concerned with dose integration, the latter approach was adopted here without loss of computational accuracy.

$\dagger$ Pitsford Hall Weather Station.

c/o Pitsford School, Moulton Lane, Pitsford, Northampton NN6 9AX, UK. www.northantsweather.org.uk 


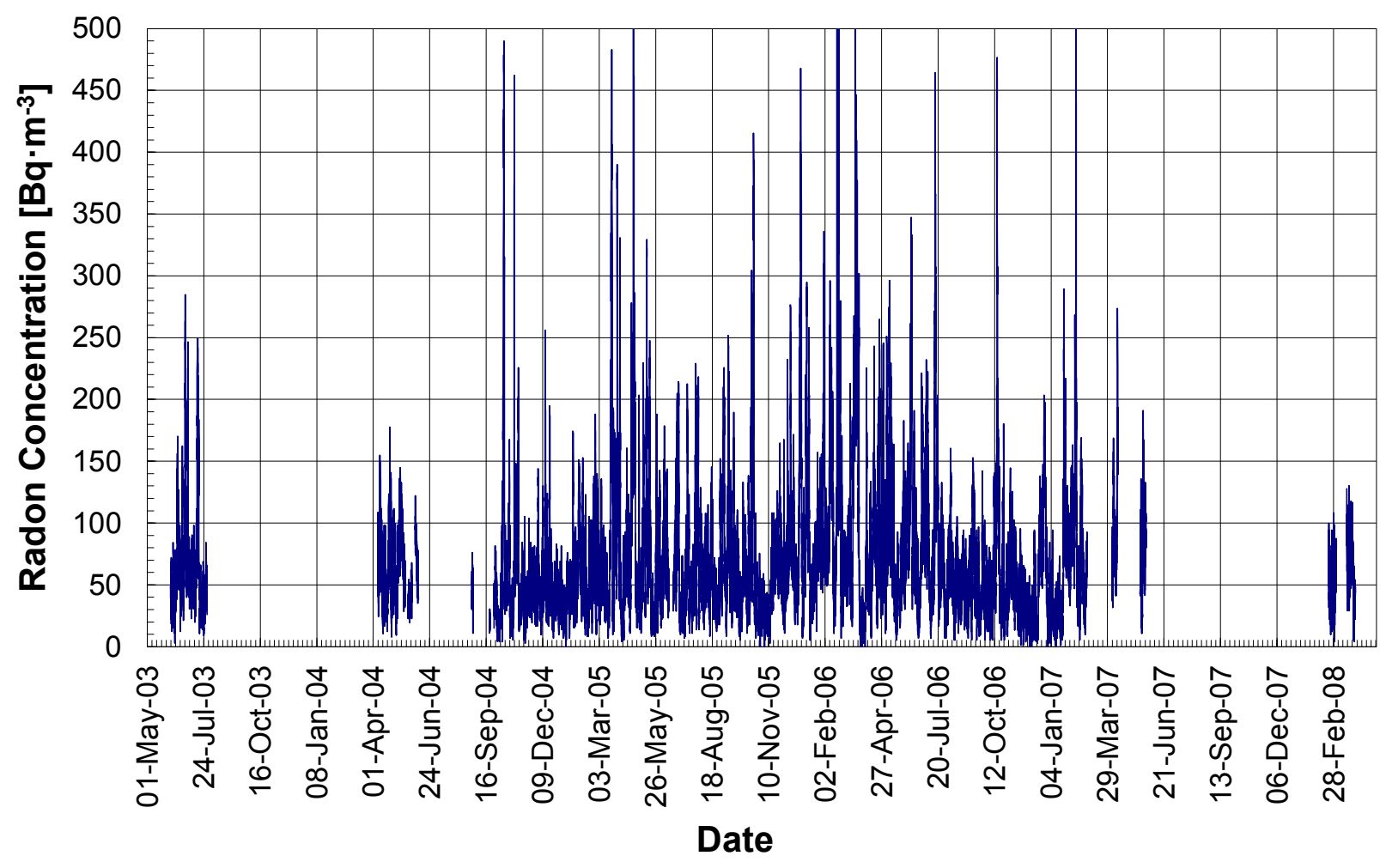

Figure 1: Radon concentration time-series, June 2003 - March 2008.

The raw hourly data were processed to provide arithmetic mean and standard deviation of radon concentration and ambient temperature on daily, monthly (calendar) and annual bases, individual monthly results over the full investigation period being summarised in Table 2. Data for corresponding calendar months throughout the measurement period were aggregated and averaged, providing month-by-month statistics, shown in Table 3. On those occasions at the beginning and end of measuring periods where only part-day radon data was available, the curve-fitted daily cycle was used to interpolate daily mean radon levels. Data for months for which only a few days' data was available (Jun/Aug/Sep 2004, Apr/May 2007, Feb 2008) were excluded from further analysis.

Hourly radon exhibits a left-skewed distribution (Figure 2), confirmed as closely lognormal by the extensive linear central portion of the inset normal probability (Q-Q) plot (Wilk and Gnanadesikan, 1968), with geometric mean radon concentration of $56.5 \mathrm{~Bq} \cdot \mathrm{m}^{-3}$. Although lognormal behaviour is characteristically associated with multiple independent influencing factors (Miles, 1998), arithmetic mean and standard deviation (St. Dev.) are employed in subsequent analysis and discussion for consistency with other tabulated data. Mean (arithmetic) radon concentration over the full investigation period was $73.0 \mathrm{~Bq} \cdot \mathrm{m}^{-3}$ (St. Dev. $62.7 \mathrm{~Bq} \cdot \mathrm{m}^{-3}$, large owing to the seasonal variation), significantly below the UK Workplace Action Level of $400 \mathrm{~Bq} \cdot \mathrm{m}^{-3}$. The mean Test Room temperature, relatively stable throughout the investigation period, was $26.2{ }^{\circ} \mathrm{C}$ (St. Dev. $1.7^{\circ} \mathrm{C}$ ). 


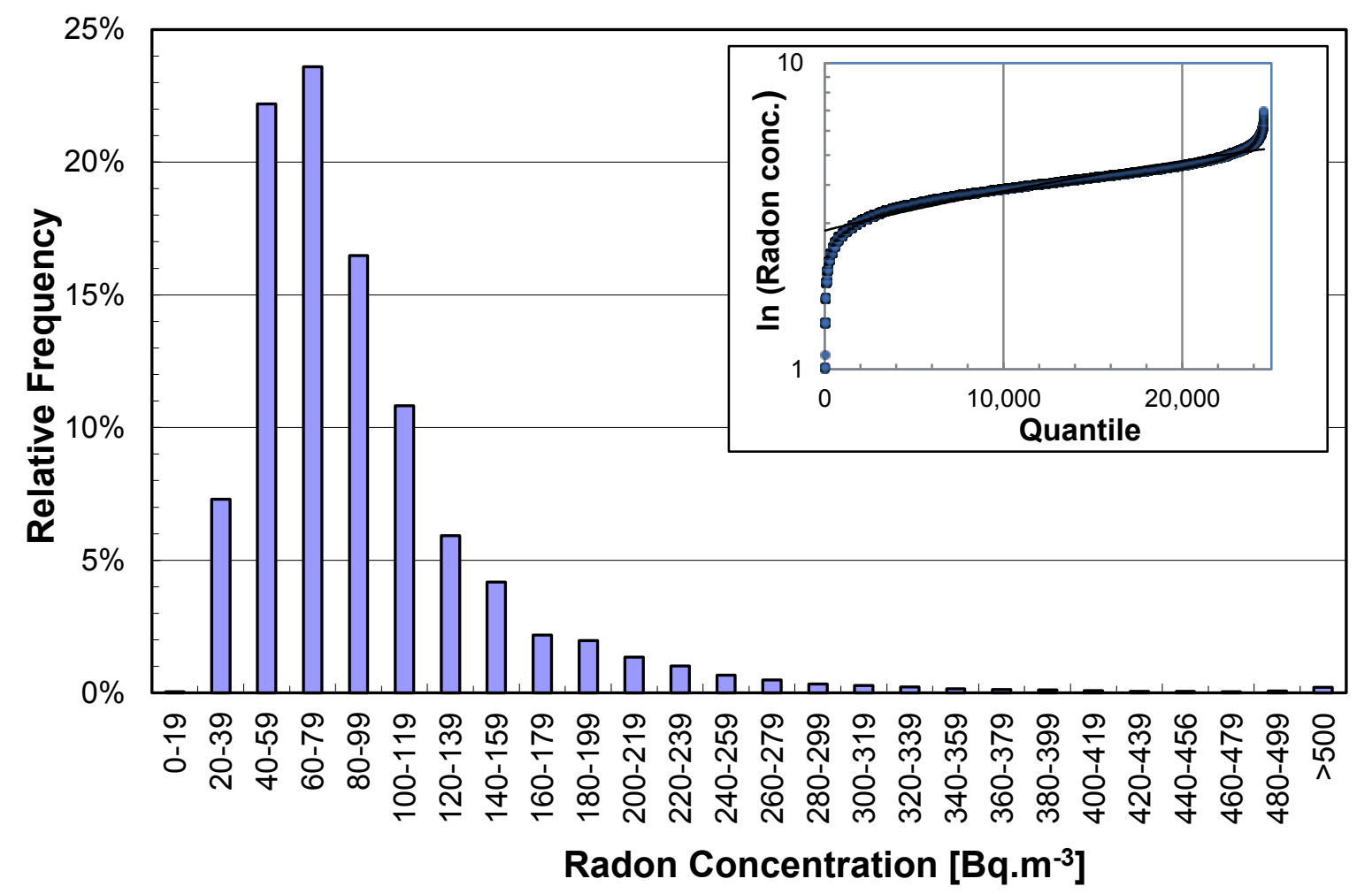

Figure 2: Lognormal distribution of hourly radon concentration in Test Room. Inset shows normal probability (Q-Q) plot confirming near-normal distribution of logarithms of radon concentrations.

\subsection{Climate Time-Series}

Figure 3 plots monthly arithmetic mean values of the principal climatic parameters (external air temperature, relative humidity, precipitation, atmospheric pressure and wind-speed) over the investigation period, demonstrating their intrinsic seasonality. Particularly evident are the annual cycles of air temperature (minimum in February, maximum in August), and wind-speed and relative humidity (both approximately in antiphase to temperature). Precipitation and atmospheric pressure exhibit less systematic behaviour. Raw data were processed to provide arithmetic mean and standard deviation for the climatic parameters, individual monthly data and aggregate month-bymonth results over the full investigation period being included with the corresponding radon data in Table 2 and Table 3 respectively. In the absence of hourly weather station data, analysis was possible only on daily, monthly (calendar) and annual bases. 
Table 2: Radon and climatic parameters - statistical analysis over full investigation period (Individual Months)

\begin{tabular}{|c|c|c|c|c|c|c|c|c|c|}
\hline Month & Year & $\begin{array}{l}\text { Radon } \\
{\left[\mathrm{Bq} \mathrm{m}^{-3}\right]}\end{array}$ & $\begin{array}{c}\text { Internal } \\
\text { Temp. } \\
{[\mathrm{C}]}\end{array}$ & $\begin{array}{l}\text { Temp. } \\
\text { Diff. } \\
{\left[{ }^{\circ} \mathrm{C}\right]} \\
\end{array}$ & $\begin{array}{c}\text { External } \\
\text { Temp. } \\
{[\mathrm{C}]}\end{array}$ & $\begin{array}{c}\text { Atmos. } \\
\text { Pressure } \\
\text { [mbar }]\end{array}$ & $\begin{array}{c}\text { Precipit- } \\
\text { ation } \\
{[\mathrm{mm}]}\end{array}$ & $\begin{array}{l}\text { Wind } \\
\text { speed } \\
{[\mathrm{knot}]}\end{array}$ & $\begin{array}{c}\text { Relative } \\
\text { Humidity } \\
{[\%]}\end{array}$ \\
\hline June & 2003 & 72.8 & 25.4 & 8.7 & 16.7 & 1014.1 & 50.8 & 5.4 & 74.5 \\
\hline July & 2003 & 61.2 & 26.4 & 8.2 & 18.2 & 1013.4 & 51.0 & 5.9 & 78.0 \\
\hline April & 2004 & 66.7 & 25.5 & 15.6 & 9.9 & 1011.2 & 68.7 & 7.4 & 80.2 \\
\hline May & 2004 & 62.8 & 27.6 & 15.1 & 12.5 & 1015.2 & 43.6 & 5.0 & 77.1 \\
\hline October & 2004 & 73.1 & 23.8 & 12.9 & 10.9 & 1006.6 & 118.4 & 8.9 & 91.0 \\
\hline November & 2004 & 48.1 & 23.8 & 16.3 & 7.5 & 1022.8 & 39.7 & 6.1 & 92.4 \\
\hline December & 2004 & 54.5 & 23.3 & 18.1 & 5.2 & 1018.0 & 19.6 & 7.0 & 93.3 \\
\hline January & 2005 & 45.9 & 23.3 & 17.7 & 5.6 & 1021.1 & 23.6 & 12.7 & 90.6 \\
\hline February & 2005 & 65.7 & 26.1 & 22.1 & 4.0 & 1021.7 & 41.5 & 8.6 & 90.1 \\
\hline March & 2005 & 92.3 & 25.6 & 18.7 & 6.9 & 1016.1 & 32.0 & 8.8 & 89.5 \\
\hline April & 2005 & 92.5 & 25.9 & 16.3 & 9.6 & 1013.0 & 34.4 & 9.0 & 81.2 \\
\hline May & 2005 & 72.5 & 26.0 & 14.5 & 11.5 & 1016.3 & 43.6 & 8.9 & 76.5 \\
\hline June & 2005 & 71.4 & 25.9 & 9.9 & 16.0 & 1018.8 & 57.5 & 6.0 & 76.5 \\
\hline July & 2005 & 64.0 & 27.0 & 10.0 & 17.0 & 1015.5 & 47.9 & 7.4 & 77.5 \\
\hline August & 2005 & 56.1 & 26.7 & 10.0 & 16.7 & 1018.1 & 54.7 & 6.2 & 77.6 \\
\hline September & 2005 & 75.9 & 26.6 & 11.1 & 15.5 & 1018.1 & 76.6 & 4.7 & 86.0 \\
\hline October & 2005 & 70.5 & 24.8 & 11.5 & 13.3 & 1014.7 & 50.3 & 6.2 & 91.3 \\
\hline November & 2005 & 50.7 & 24.8 & 18.8 & 6.0 & 1015.7 & 34.4 & 7.8 & 94.1 \\
\hline December & 2005 & 92.4 & 25.5 & 21.3 & 4.2 & 1017.9 & 34.6 & 8.1 & 92.7 \\
\hline January & 2006 & 97.5 & 25.4 & 21.3 & 4.1 & 1023.3 & 17.7 & 6.9 & 92.9 \\
\hline February & 2006 & 139.6 & 25.5 & 21.7 & 3.8 & 1016.4 & 33.0 & 8.1 & 90.2 \\
\hline March & 2006 & 113.0 & 25.8 & 20.9 & 4.9 & 1010.0 & 42.0 & 9.7 & 82.0 \\
\hline April & 2006 & 86.4 & 25.9 & 16.8 & 9.1 & 1015.0 & 39.4 & 8.9 & 80.3 \\
\hline May & 2006 & 83.9 & 26.9 & 14.1 & 12.8 & 1012.7 & 80.9 & 7.1 & 78.2 \\
\hline June & 2006 & 100.0 & 26.5 & 9.5 & 17.0 & 1020.9 & 4.9 & 3.7 & 71.6 \\
\hline July & 2006 & 95.1 & 28.9 & 8.3 & 20.6 & 1018.2 & 73.7 & 4.4 & 68.1 \\
\hline August & 2006 & 51.0 & 28.1 & 11.6 & 16.5 & 1012.5 & 73.2 & 8.6 & 81.5 \\
\hline September & 2006 & 51.1 & 28.1 & 10.5 & 17.6 & 1012.9 & 49.5 & 5.2 & 85.4 \\
\hline October & 2006 & 62.8 & 27.9 & 14.8 & 13.1 & 1009.4 & 70.0 & 6.5 & 91.2 \\
\hline November & 2006 & 48.4 & 27.9 & 20.0 & 7.9 & 1013.1 & 75.5 & 9.3 & 91.7 \\
\hline December & 2006 & 57.9 & 26.9 & 20.7 & 6.2 & 1018.4 & 64.3 & 9.1 & 92.1 \\
\hline January & 2007 & 54.8 & 27.2 & 20.5 & 6.7 & 1014.9 & 66.4 & 10.3 & 89.4 \\
\hline February & 2007 & 87.2 & 28.1 & 22.3 & 5.8 & 1007.0 & 69.8 & 6.8 & 93.4 \\
\hline March & 2008 & 63.1 & 26.8 & 20.7 & 6.1 & 1006.1 & 66.3 & 9.2 & 82.9 \\
\hline Mean & & 73.0 & 27.4 & 15.8 & 11.6 & 1013.4 & 61.2 & 7.4 & 83.8 \\
\hline St. Dev. & & 21.1 & 0.9 & 5.0 & 5.3 & 4.5 & 21.1 & 2.1 & 8.3 \\
\hline
\end{tabular}



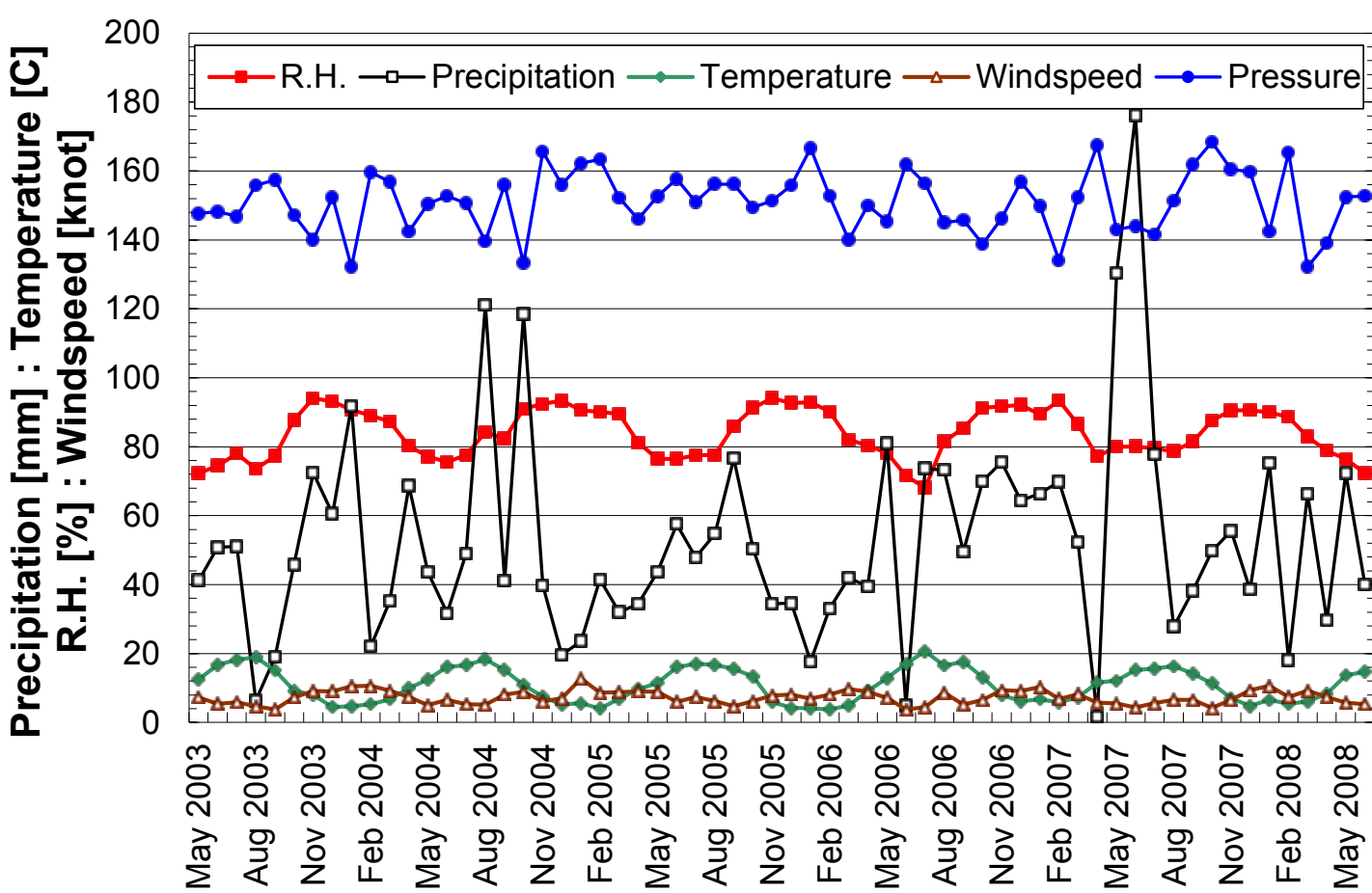

\section{Calendar Month}

Figure 3: Climatic parameter time-series, Pitsford Hall Weather Station, June 2003-March 2008.

Table 3: Radon and climatic parameters - statistical analysis over full investigation period (aggregate months)

\begin{tabular}{lcccccccc}
\hline \hline Month & Radon & $\begin{array}{c}\text { Internal } \\
\text { Temp. } \\
{[\mathrm{C}]}\end{array}$ & $\begin{array}{c}\text { Temp. } \\
\text { Diff. } \\
{\left[{ }^{\circ} \mathrm{C}\right]}\end{array}$ & $\begin{array}{c}\text { External } \\
\text { Temp. } \\
{[\mathrm{C}]}\end{array}$ & $\begin{array}{c}\text { Atmos. } \\
\text { Pressure } \\
{[\mathrm{mbar}]}\end{array}$ & $\begin{array}{c}\text { Precipit- } \\
\text { ation } \\
{[\mathrm{mm}]}\end{array}$ & $\begin{array}{c}\text { Wind } \\
\text { speed } \\
{[\mathrm{knot}]}\end{array}$ & $\begin{array}{c}\text { Relative } \\
\text { Humidity } \\
{[\%]}\end{array}$ \\
\hline January & 66.1 & 25.3 & 19.9 & 5.5 & 1019.8 & 35.9 & 10.0 & 91.0 \\
February & 97.5 & 26.6 & 22.0 & 4.5 & 1015.0 & 48.1 & 7.8 & 91.2 \\
March & 89.4 & 26.1 & 20.1 & 6.0 & 1010.7 & 46.8 & 9.2 & 84.8 \\
April & 81.8 & 25.8 & 16.2 & 9.5 & 1013.1 & 47.5 & 8.4 & 80.6 \\
May & 73.1 & 26.8 & 14.5 & 12.3 & 1014.7 & 56.0 & 7.0 & 77.3 \\
June & 81.4 & 26.0 & 9.4 & 16.6 & 1017.9 & 37.7 & 5.0 & 74.2 \\
July & 73.4 & 27.4 & 8.8 & 18.6 & 1015.7 & 57.5 & 5.9 & 74.5 \\
August & 53.5 & 27.4 & 10.8 & 16.6 & 1015.3 & 64.0 & 7.4 & 79.6 \\
September & 63.5 & 27.3 & 10.8 & 16.6 & 1015.5 & 63.1 & 5.0 & 85.7 \\
October & 68.8 & 25.5 & 13.0 & 12.4 & 1010.2 & 79.6 & 7.2 & 91.2 \\
November & 49.1 & 25.5 & 18.4 & 7.1 & 1017.2 & 49.9 & 7.7 & 92.7 \\
December & 68.3 & 25.2 & 20.0 & 5.2 & 1018.1 & 39.5 & 8.1 & 92.7 \\
\hline \hline Mean & 72.2 & 26.2 & 15.3 & 10.9 & 1015.3 & 52.1 & 7.4 & 84.6 \\
St. Dev. & 13.9 & 0.8 & 4.7 & 5.2 & 2.9 & 12.6 & 1.5 & 7.2 \\
\hline \hline
\end{tabular}

\section{Analysis and Discussion}

\subsection{Temperature-Based SCFs}

The stable thermal environment of the Test Room offered the opportunity for a comparison of the various approaches to the definition and determination of SCFs, particularly the temperature-based correction defined in Eq. 2. 
Using the available data, functionally equivalent SCF sets were derived:

1. Directly from the normalised mean monthly radon concentration in the Test Room.

2. Using the formula of Eq. 2 in conjunction with the mean monthly external temperature at Pitsford School Weather Station.

3. Using the formula of Eq. 2 in conjunction with the mean monthly temperature difference between Pitsford School Weather Station and the Test Room.

These are summarised in Table 4, together with the original (1988) and revised $(2012,2014)$ published domestic SCF sets, and all five sets are compared graphically in Figure 4. Most noticeable is the time-shift between the radon-derived SCF set and those derived from temperature data, the radon-derived SCFs peaking in October-November, four months later than the temperature-based sets. Somewhat surprisingly, given the relative temperature stability of the Test Room, the two temperature-related SCF sets are also noticeably different, the annual variance of the temperature-based set being somewhat greater than that of the temperature-difference, although the two show relatively good correlation $(r=0.82)$. The inclusion of the published domestic SCF sets provides what is believed to be the first experimental comparison of the tabulated SCFs and temperature-derived correction approaches. These show consistent behaviour, showing maxima in mid-summer and minima in mid-winter.

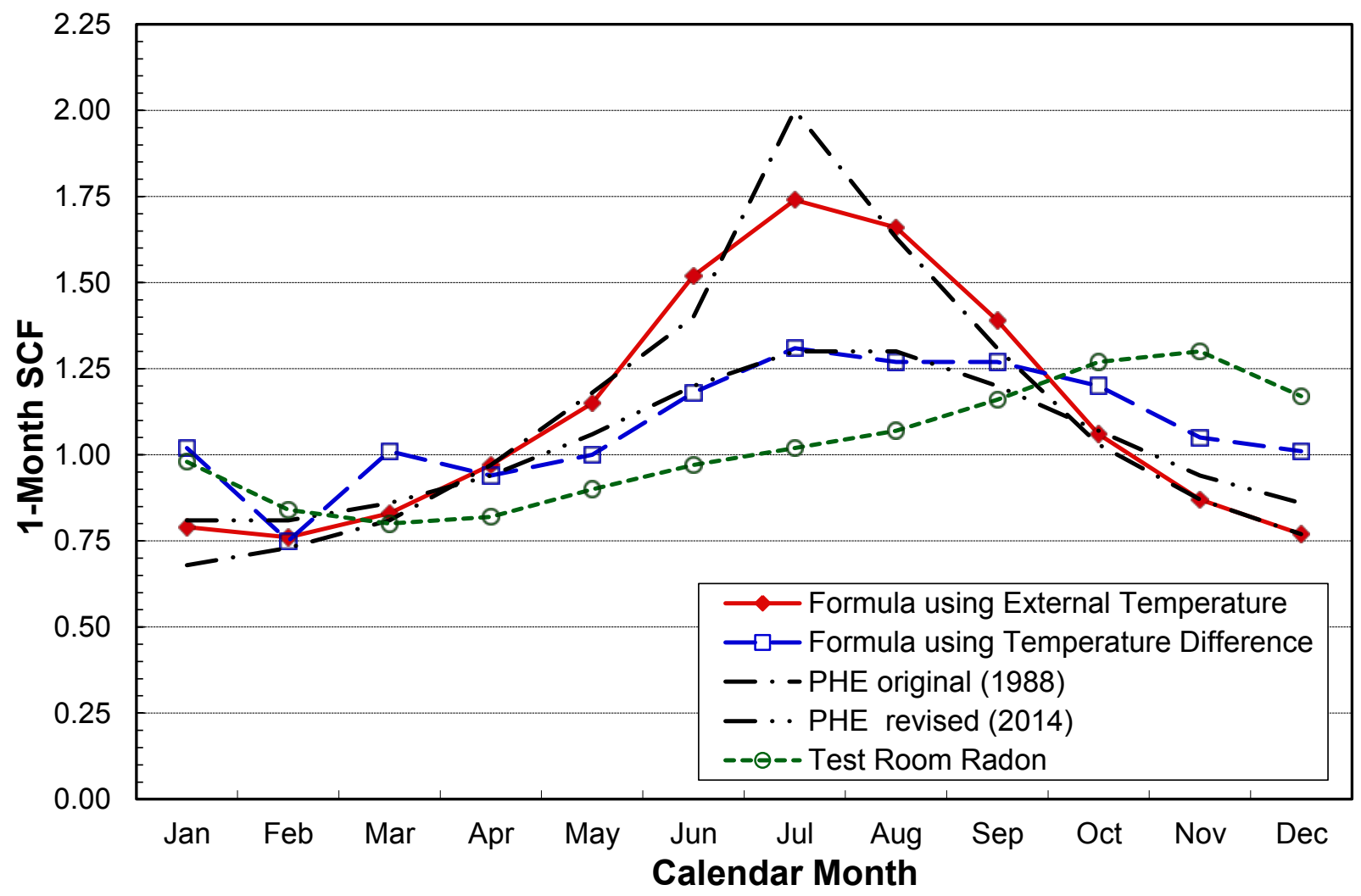

Figure 4: SCF sets derived from temperature data using Eq.2, aggregate mean monthly radon, and published PHE/HPA tabulations. 
Table 4: Summary of Northamptonshire and tabulated domestic SCF sets

\begin{tabular}{|c|c|c|c|c|c|c|c|c|c|c|c|c|}
\hline & Jan & Feb & Mar & Apr & May & Jun & Jul & Aug & Sep & Oct & Nov & Dec \\
\hline Test Room Radon & 0.98 & 0.84 & 0.80 & 0.82 & 0.90 & 0.97 & 1.02 & 1.07 & 1.16 & 1.27 & 1.30 & 1.17 \\
\hline $\begin{array}{l}\text { Formula using External } \\
\text { Temperature }\end{array}$ & 0.79 & 0.76 & 0.83 & 0.97 & 1.15 & 1.52 & 1.74 & 1.66 & 1.39 & 1.06 & 0.87 & 0.77 \\
\hline $\begin{array}{l}\text { Formula using } \\
\text { Temperature Difference }\end{array}$ & 1.02 & 0.75 & 1.01 & 0.94 & 1.00 & 1.18 & 1.31 & 1.27 & 1.27 & 1.20 & 1.05 & 1.01 \\
\hline $\begin{array}{l}\text { PHE/HPA } \\
(1988)\end{array}$ & 0.68 & 0.73 & 0.81 & 0.97 & 1.18 & 1.40 & 2.00 & 1.63 & 1.31 & 1.03 & 0.87 & 0.77 \\
\hline PHE/HPA revised (2014) & 0.81 & 0.81 & 0.86 & 0.94 & 1.06 & 1.20 & 1.30 & 1.30 & 1.20 & 1.07 & 0.94 & 0.86 \\
\hline
\end{tabular}

Table 5 presents a matrix of the correlation coefficients for these data sets. SCFs derived from experimental radon concentration data show poor correlation with SCFs derived from either the external temperature $(r=0.11)$ or either of the $1988(r=0.10)$ or 2012-2014 $(r=0.02)$ domestic SCF sets, but show moderate correlation $(r=0.50)$ with SCFs derived from the temperature difference. This correlation indicates that the temperature difference between the Test Room and the external environment provides, via the corresponding pressure difference, the primary force driving radon ingress, a view recently supported by Vasilyev and Zhukovsky (2013) who showed that, in a closed room, temperature-difference dependence of radon accumulation is indicative of the dominance of advection over diffusion as the radon source. This is consistent with the known parameters of the Test Room, particularly its location at or below ground-level, and its assumed constructional details. Furthermore, in applying Equation 2, better representation of the actual seasonal correction to be applied in any particular case is achieved by using the temperature difference between the Test Room and the external environment, as might be intuitively expected, rather than by using the absolute external temperature.

Table 5: Inter-SCF Correlation Coefficients, $r$, for Northamptonshire and domestic SCF tabulations

\begin{tabular}{llccccc}
\hline \hline & & \multicolumn{2}{c}{ Formula } & \multicolumn{2}{c}{ PHE/HPA } \\
\cline { 3 - 6 } & & Test & External & Temperature & Original & Revised \\
& & Room & Temperature & Difference & $(1988)$ & $(2012-14)$ \\
\hline \multirow{2}{*}{ Test Room } & 1.00 & 0.11 & 0.50 & 0.09 & 0.25 \\
\multirow{2}{*}{ Formula } & External Temperature & 0.11 & 1.00 & 0.82 & 0.97 & 0.98 \\
& Temperature Difference & 0.50 & 0.82 & 1.00 & 0.79 & 0.86 \\
PHE/HPA original (1988) & 0.09 & 0.97 & 0.79 & 1.00 & 0.95 \\
PHE/HPA revised (2014) & 0.25 & 0.98 & 0.86 & 0.95 & 1.00 \\
\hline \hline
\end{tabular}

As might be expected given its provenance, the SCF set derived using AM monthly external temperature data provides near-perfect correlation $(r=0.97 \pm 0.02)$ with both of the PHE-derived domestic SCF sets. This observation suggests that, particularly for month-long time-integrating radon determinations, the complexity of deriving SCFs from temperature data is outweighed by the convenience of using the existing domestic SCF sets. Somewhat poorer correlation $(r=0.77 \pm 0.02)$ exists between SCFs derived from the internal-external temperature difference and the existing sets.

Note, finally, that the comparisons and correlations presented here are between SCFs derived from a single workplace environment, albeit with all issues associated with occupancy removed, and SCFs 
developed from domestic housing using an aggregated approach involving many thousands of individual domestic radon determinations, each of which is subjected to individual occupancy-based perturbations (Denman et al., 2007b). Denman (2008) showed that, although there are significant exceptions where the standard domestic SCF does not apply, there is no inherent reason to believe that domestic and workplace radon variations should be significantly different, although differing occupancy patterns and building size might make subtle changes to seasonal variation.

\subsection{Radon and Climate}

Figure 3 demonstrates that certain climatic parameters show marked annual periodicity, with external air temperature exhibiting maximum and minimum values in August and February respectively and wind-speed and relative humidity approximately in antiphase to external air temperature. Table 6 presents the correlations between mean radon and the set of climatic parameters for individual (a) and aggregate (b) months.

Table 6: Pearson correlation matrix for radon and climatic parameters

(a) Individual Months

\begin{tabular}{lrrrrrrrr}
\hline \hline & \multirow{2}{*}{ Radon } & $\begin{array}{c}\text { Internal } \\
\text { Temp. }\end{array}$ & $\begin{array}{c}\text { Temp. } \\
\text { Diff. }\end{array}$ & $\begin{array}{r}\text { External } \\
\text { Temp. }\end{array}$ & $\begin{array}{c}\text { Atmos. } \\
\text { Pressure }\end{array}$ & $\begin{array}{r}\text { Precipit- } \\
\text { ation }\end{array}$ & $\begin{array}{c}\text { Wind } \\
\text { speed }\end{array}$ & $\begin{array}{c}\text { Rel. } \\
\text { Humidity }\end{array}$ \\
\hline Radon & 1.00 & 0.01 & 0.18 & -0.17 & -0.01 & -0.23 & -0.10 & -0.16 \\
Temp. Int. & 0.01 & 1.00 & -0.17 & 0.44 & -0.29 & 0.35 & -0.29 & -0.38 \\
Temp. Diff. & 0.18 & -0.17 & 1.00 & -0.96 & -0.02 & -0.20 & 0.62 & 0.69 \\
Temp. Ext. & -0.17 & 0.44 & -0.96 & 1.00 & -0.06 & 0.28 & -0.65 & -0.73 \\
Atm. Press. & -0.01 & -0.29 & -0.02 & -0.06 & 1.00 & -0.61 & -0.15 & 0.02 \\
Rainfall & -0.23 & 0.35 & -0.20 & 0.28 & -0.61 & 1.00 & 0.02 & -0.03 \\
Wind-Speed & -0.10 & -0.29 & 0.62 & -0.65 & -0.15 & 0.02 & 1.00 & 0.42 \\
Rel. Humidity & -0.16 & -0.38 & 0.69 & -0.73 & 0.02 & -0.03 & 0.42 & 1.00 \\
\hline \hline
\end{tabular}

(b) Aggregate Months

\begin{tabular}{lrrrrrrrr}
\hline \hline & \multirow{2}{*}{ Radon } & $\begin{array}{c}\text { Internal } \\
\text { Temp. }\end{array}$ & $\begin{array}{c}\text { Temp. } \\
\text { Diff. }\end{array}$ & $\begin{array}{c}\text { External } \\
\text { Temp. }\end{array}$ & $\begin{array}{c}\text { Atmos. } \\
\text { Pressure }\end{array}$ & $\begin{array}{c}\text { Precipit- } \\
\text { ation }\end{array}$ & $\begin{array}{r}\text { Wind } \\
\text { speed }\end{array}$ & $\begin{array}{c}\text { Rel. } \\
\text { Humidity }\end{array}$ \\
\hline Radon & 1.00 & -0.02 & 0.29 & -0.27 & -0.34 & -0.29 & 0.10 & -0.16 \\
Temp. Int. & -0.02 & 1.00 & -0.58 & 0.68 & -0.11 & 0.42 & -0.56 & -0.59 \\
Temp. Diff. & 0.29 & -0.58 & 1.00 & -0.99 & 0.04 & -0.48 & 0.81 & 0.72 \\
Temp. Ext. & -0.27 & 0.68 & -0.99 & 1.00 & -0.06 & 0.50 & -0.81 & -0.74 \\
Atm. Press. & -0.34 & -0.11 & 0.04 & -0.06 & 1.00 & -0.63 & -0.06 & 0.06 \\
Precipitation & -0.29 & 0.42 & -0.48 & 0.50 & -0.63 & 1.00 & -0.35 & -0.03 \\
Wind-Speed & 0.10 & -0.56 & 0.81 & -0.81 & -0.06 & -0.35 & 1.00 & 0.51 \\
Rel. Humidity & -0.16 & -0.59 & 0.72 & -0.74 & 0.06 & -0.03 & 0.51 & 1.00 \\
\hline \hline
\end{tabular}

In summary, the mean radon concentration for individual months shows:

- low negative correlation with precipitation $(r=-0.23)$, external temperature $(r=-0.17)$ and relative humidity $(r=-0.16)$

- very low negative correlation $(r=-0.10)$ with wind-speed

- no/negligible correlation with internal temperature $(r=0.01)$ and atmospheric pressure $(r=$ $0.01)$ 
In contrast, mean radon concentration for aggregated months shows noticeably different behaviour:

- moderate to low negative correlation with atmospheric pressure $(r=-0.34)$, precipitation $(r=-0.29)$ and external temperature $(r=-0.27)$

- low to very low negative correlation with relative humidity $(r=-0.16)$ and low positive correlation with wind-speed $(r=0.10)$

- no/negligible correlation with internal temperature $(r=-0.02)$

Table 6 confirms that correlation between mean monthly radon concentration and any of the climatic parameters (on both individual and aggregate bases) is moderate at best. Over aggregate months, mean radon correlates best with atmospheric pressure $(r=-0.34)$, with precipitation $(r=$ $0.29)$ and external temperature $(r=-0.27)$ showing progressively poorer correlation; the remaining climatic correlation coefficients fall in the range $0.01<|r|<0.16$. Over individual months, a somewhat different picture emerges, with mean radon showing best negative correlation with precipitation $(r=-0.23)$, followed by external temperature $(r=-0.17)$, relative humidity $(r=-0.16)$ and wind-speed $(r=-0.10)$. In contrast with aggregate months, where correlation with atmospheric pressure is significant, correlation with atmospheric pressure over individual months is zero. Correlation with internal temperature and wind-speed is essentially zero over both individual and aggregated months; this is not surprising since the Test Room has no external ventilation, with minimal temperature fluctuation during the study period.

To estimate a site-specific SCF set, aggregate monthly radon data from Table 3 (plotted as columns in Figure 5) were numerically fitted to a pure 12-month sinusoidal model (solid line). Table 7 summarises the correlation coefficients (and associated $p$-values) of the 12-month sinusoid profile with the available normalised climatic and radon parameters, showing good correlation $(r>0.8)$ with the majority of the available annual climatic parameter profiles. Significant exceptions are atmospheric pressure $(r=0.20, p=53.67 \%)$ and, to lesser extents, precipitation $(r=0.65$, $p=2.14 \%)$ and internal temperature $(\mathrm{r}=0.70, \mathrm{p}=1.09 \%)$. Correlation coefficients of the fitted radon profile with the arithmetic and geometric radon means are $r=0.77(p=0.34 \%)$ and $r=0.79$ $(p=0.21 \%)$ respectively. AS table 7 shows, introduction of an additional 6-month sinusoid (i.e. second harmonic) to the model, plotted as the dashed curve in Figure 5, results in significantly increased correlation with atmospheric pressure $(r=0.84, p=0.062 \%)$, precipitation $(r=0.86$, $p=0.033 \%)$ and internal temperature $(r=0.87, p=0.021 \%)$; all other climatic correlations remaining essentially unchanged. In addition, inclusion of the 6-month second-harmonic sinusoid improves the fit to the radon data by approximately $4-5 \%$. 


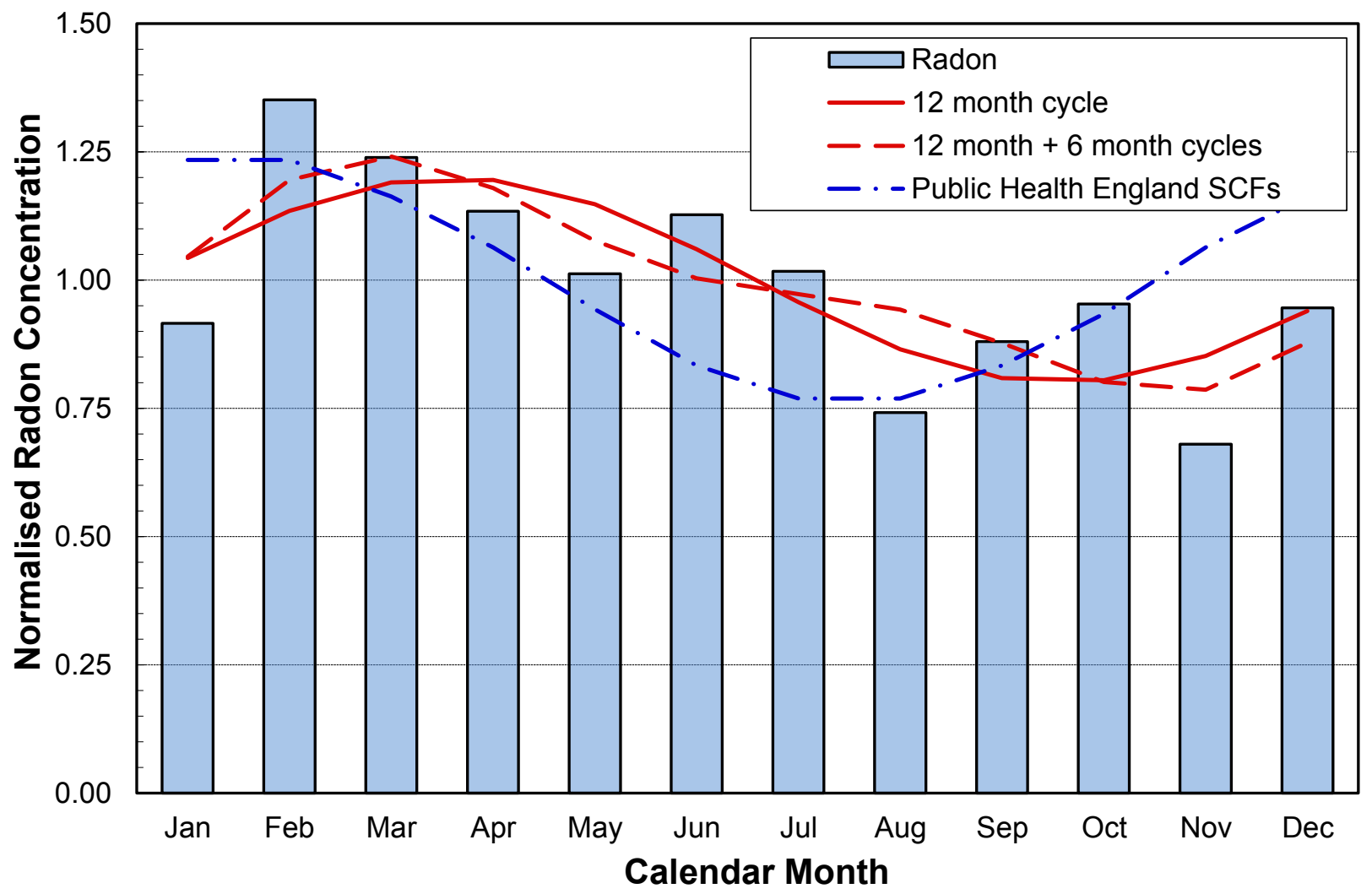

Figure 5: Normalised mean monthly radon fitted to 12-month sinusoid and 12+6-month hybrid sinusoid functions.

Table 7: Pearson correlation coefficents for sinusoidal radon models with normalised radon and climatic parameters, and improvement (in $r$ ) from inclusion of 6-month term (aggregate months)

\begin{tabular}{l|cc|cc|c}
\hline \hline & \multicolumn{2}{|c|}{ 12-month sinusoid } & 12- \& 6- month sinusoids & Improvement \\
\hline & $r$ & $p$-value & $r$ & $p$-value & $\%$ \\
\hline External Temperature & 0.97 & $0.00 \%$ & 0.99 & $0.00 \%$ & 2.1 \\
Internal Temperature & 0.70 & $1.09 \%$ & 0.87 & $0.02 \%$ & 24 \\
Temperature Difference & 0.98 & $0.00 \%$ & 0.98 & $0.00 \%$ & 0.0 \\
Atmospheric Pressure & 0.20 & $53.67 \%$ & 0.84 & $0.06 \%$ & 320 \\
Precipitation & 0.65 & $2.14 \%$ & 0.86 & $0.03 \%$ & 32 \\
Wind-speed & 0.80 & $0.15 \%$ & 0.81 & $0.13 \%$ & 1.3 \\
Relative Humidity & 0.98 & $0.00 \%$ & 0.99 & $0.00 \%$ & 1.0 \\
Vapour Pressure & 0.97 & $0.00 \%$ & 0.98 & $0.00 \%$ & 1.0 \\
Dew Point & 0.98 & $0.00 \%$ & 0.99 & $0.00 \%$ & 1.0 \\
\hline Radon - arithmetic mean & 0.77 & $0.34 \%$ & 0.81 & $0.15 \%$ & 5.2 \\
Radon - geometric mean & 0.79 & $0.21 \%$ & 0.82 & $0.10 \%$ & 3.8 \\
\hline \hline
\end{tabular}

\subsection{Latency and Lag}

The observation (Figure 4) that the maximum SCF for radon in the Test Room lagged behind those derived from temperature parameters by nearly four months prompted a more detailed investigation of lagged correlation between radon and climate and, in particular, between radon and parameters representing the total atmospheric moisture content. In order to elucidate the effects of atmospheric 
moisture content, the derived quantities vapour pressure, calculated from the external temperature and atmospheric pressure, and dew point, calculated from the external temperature and the relative humidity (Buck, 1981), were included.

The optimum time-shift, quantised to whole months, for each parameter was determined from correlation calculations, results of which are summarised in Table 8. Best-fit shifts ranged from 1 month for atmospheric pressure and precipitation to 4 months for internal temperature and relative humidity. Figure 6 shows the aggregate monthly radon results in normalised form, essentially the inverse of the SCF plot of Figure 4, together with normalised and time-shifted plots of a number of climatic parameters, all centred on the mid-year June-July boundary.

Table 8: Best-fit correlation between time-shifted radon and climatic parameters (radon lags climate parameters)

\begin{tabular}{lccc}
\hline \hline & Radon Lag & $r$ & $p$-value \\
\hline & (months) & & \\
\hline External Temperature & 2 & -0.59 & $0.11 \%$ \\
Internal Temperature & 4 & -0.46 & $1.97 \%$ \\
Temperature Difference & 2 & 0.60 & $0.10 \%$ \\
Atmospheric Pressure & 1 & 0.34 & $6.39 \%$ \\
Precipitation & 1 & -0.47 & $0.90 \%$ \\
Wind-speed & 2 & 0.41 & $3.40 \%$ \\
Relative Humidity & 4 & 0.57 & $0.25 \%$ \\
Vapour Pressure & 2 & -0.59 & $0.11 \%$ \\
Dew Point & 2 & -0.64 & $0.08 \%$ \\
\hline \hline
\end{tabular}




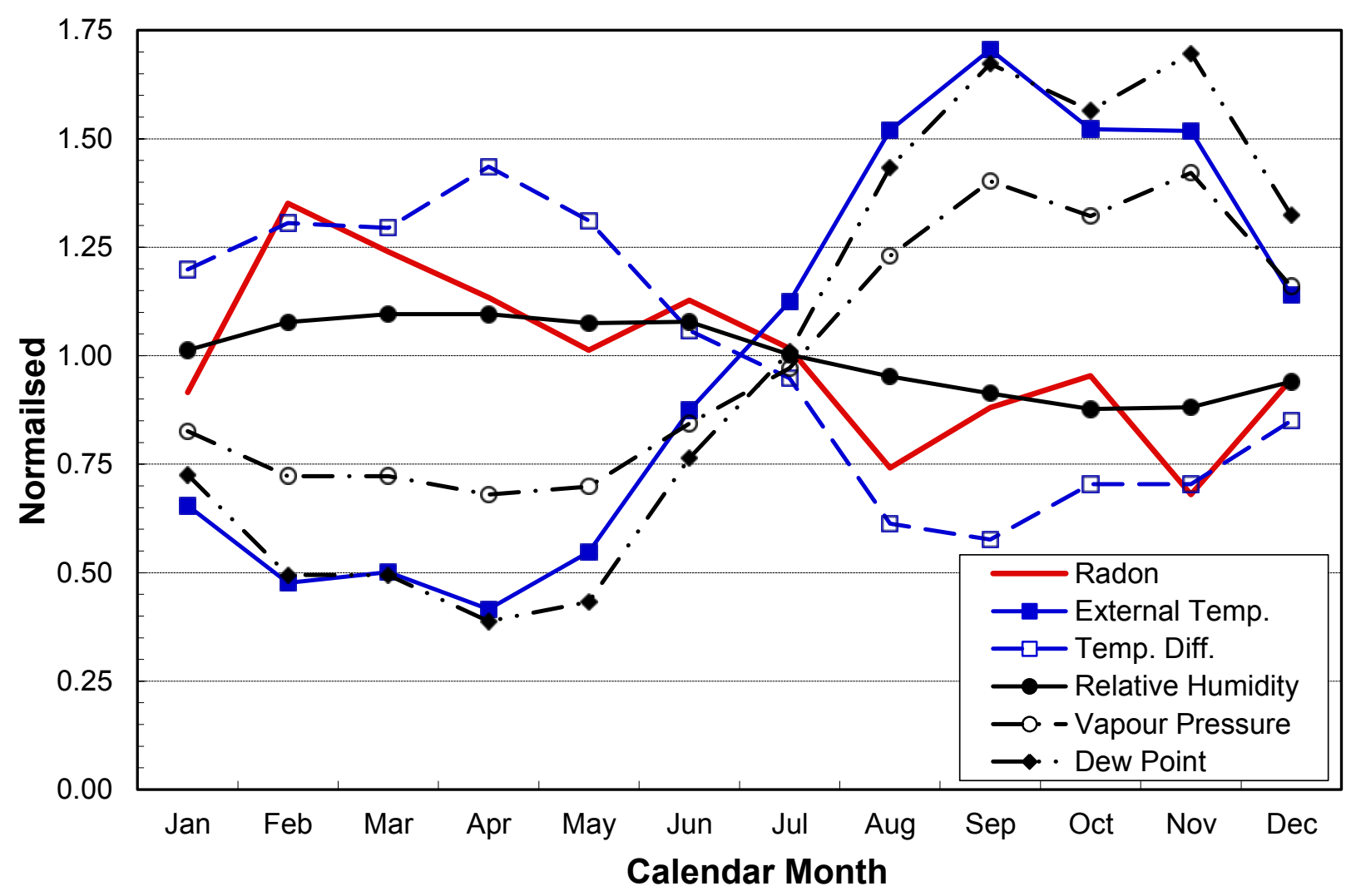

Figure 6: Normalised mean monthly radon, together with time-shifted normalised climatic parameters (to show lagged relationship with radon).

All three measures of atmospheric moisture content correlate moderately well with radon concentration, as shown in Table 8. However, the shorter lag and higher significance of the correlations between radon and vapour pressure and dew point, on the one hand, compared to relative humidity, on the other (Table 8), lead to the conclusion that the principal climatic driver for radon in the Test Room is total atmospheric moisture content rather than relative humidity, with a possible temperature (difference) interaction. Also, although not derived here, other measures of atmospheric moisture content, such as vapour density, might be more appropriate than vapour pressure or dew point.

Perrier and Girault (2013) have recently demonstrated that radon flux and concentration in the soil are sensitive to atmospheric pressure variations, particularly to periodic phenomena such as the semi-diurnal barometric tide S2 (Simpson, 1919), and have analysed radon response to barometric oscillations in a horizontal layer over a half-space, representing the situation where a soil layer overlays homogeneous bedrock, taking into account air and water phases and the presence of static vertical advection. Although radon modulation amplitudes are generally small and difficult to detect, situations may exist where the amplitudes of low-order harmonics exceed $100 \mathrm{~Bq} \mathrm{~m}^{-3}$, leading, for example, to possible detection of periodicity in the radon power spectra associated with S2. The presence of an interface significantly influences the response to barometric oscillations, a significant negative phase shift in the surface radon flux being introduced in the presence of a shallow interface, while radon flux is almost in phase opposition with atmospheric pressure over a homogeneous half-space. In the absence of detailed knowledge of the subsoil and bed-rock conditions beneath the Test Room, it is difficult to draw firm conclusions regarding the cause of the radon lag observed here. However, it is apparent that the basis of a sound theoretical background for the observed behaviour may now be available. 


\section{Conclusions}

Radon concentration and ambient temperature were monitored at hourly intervals in an environmentally-stable, rarely-visited basement in a public-service building. Sampling periods totalled 1,025 days during the period between June 2003 and March 2008 (1,766 days), the longest continuous sampling period and interval between sampling periods being 335 and 271 days respectively. Daily, monthly (calendar) and annual mean radon concentrations and internal temperatures were calculated, averages over corresponding months of at least three separate years being available for each calendar month. Corresponding meteorological parameters were generated from data collected at a weather station $10 \mathrm{~km}$ from the Test Room.

SCFs derived using the temperature-based formula indicate relatively good correlation $(r=0.50)$ between radon seasonality and the internal-external temperature difference, but poorer correlation $(r=0.10)$ with absolute external temperature, the parameter implied by use of that formula. In contrast, the SCF set derived from external temperature correlates very well with both the original (1988) and the recently revised (2014) published 1-month domestic sets ( $r=0.97$ in each case), confirming that, particularly for month-long time-integrating radon determinations, the complexity of deriving SCFs from temperature data is outweighed by the convenience of using either of the existing SCF sets.

Following the conventional approach to SCF calculation, aggregate monthly radon data were numerically fitted to a pure 12-month sinusoid. The fitted radon profile showed good correlation with the majority of the available annual climatic parameter profiles; significant exceptions being atmospheric pressure, precipitation and internal temperature. Introduction of an additional 6-month sinusoid (i.e. second harmonic) to the fitting algorithm resulted in significantly increased correlation with these three parameters, all other correlations remaining essentially unchanged.

Monthly arithmetic mean radon concentration shows minimal or zero cross-correlation with the three temperature parameters, atmospheric pressure and wind-speed; there is minimal negative correlation with precipitation and possibly also with relative humidity. Significant latency in radon response is evident in respect of a number of climatic parameters, particularly those associated with the presence of atmospheric moisture. This observation is supported, at least in part, by recent theoretical modelling of radon flux in the soil/bedrock environment. Analysis suggests that the principal driver for radon in the Test Room is total atmospheric moisture content rather than relative humidity, with a possible temperature interaction with, in addition to the vapour pressure and dew point considered here, vapour density being a potential candidate parameter to characterise this.

Finally, it should be noted that the Test Room represents a unique zero-occupancy workplace situation, albeit one in which the absence of anthropogenic disturbance provides an opportunity to probe more deeply the factors influencing radon concentration levels, while published SCF tabulations derived from radon survey data represent the aggregation of many thousands of individual, and widely varying, domestic radon determinations distributed both spatially and temporally. The degree of agreement observed here between temperature-derived SCFs, particularly where actual internal-external temperature-difference rather than external temperature alone is used as the experimental variable, and the traditional tabulations, while validating the temperature-based approach for short term screening assessments, as discussed by Ibrahimi and Miles (1999a), suggests that, over longer measurement periods, little advantage is gained by introducing an additional temperature measurement into the seasonal correction process.

\section{Acknowledgements}

We wish to thank the Referees for their useful and constructive comments on the manuscript, and for drawing our attention to errors and inconsistencies in certain of the tabular data. 


\section{References}

AGIR (Advisory Group on Ionising Radiation), 2009. Radon and Public Health. Documents of the Health Protection Agency, RCE-11. ISBN: 978-0-85951-644-0.

Åkerblom, G., Andersson, P., Clevensjö, B., 1984. Soil-gas radon - a source for indoor radon daughters. Radiat. Prot. Dosim. 7, 49-54.

Azimi, D., 1996. Prediction of seasonal radon concentration from weekly screening. Indoor Built Environ. 5, 181-183. doi:10.1177/1420326X9600500309.

Baysson, H., Billon, S., Laurier, D., Rogel, A., Tirmarche, M., 2003. Seasonal correction factors for estimating radon exposure in dwellings in France. Radiat. Prot. Dosim. 104, 245-252.

Bossew, P., Lettner, H., 2007. Investigations on indoor radon in Austria, part 1: seasonality of indoor radon concentration. J. Environ. Radioact. 98, 329-245.

doi:10.1016/j.jenvrad.2007.06.006.

Buck, A., 1981. New equations for computing vapor pressure and enhancement factor. J. Appl. Meteorol. 20, 1527-1532.

Burke, O., Murphy, P., 2011. Regional variation of seasonal correction factors for indoor radon levels. Radiat. Measure. 46, 1168-1172. doi:10.1016/j.radmeas.2011.06.075.

Chen, J., 2001. Estimate of annual average radon concentration in the normal living area from short-term tests. Health Phys. 85, 740-744.

Climent, H., Tokonami, S., Furukawa, M., 1999. Statistical analysis applied to radon and natural events. Proc. Radon in the Living Environment, Athens, Greece, April 1999, 241-254.

Crockett, R.G.M., Gillmore, G.K., Phillips, P.S., Denman, A.R., Groves-Kirkby, C.J., 2006a. Radon anomalies preceeding earthquakes which occurred in the UK in the summer and autumn 2002. Sci. Tot. Environ. 364, 138-148. doi:10.1016/j.scitotenv.2005.08.003.

Crockett, R.G.M., Gillmore, G.K., Phillips, P.S., Denman, A.R., Groves-Kirkby, C.J., 2006b. Tidal synchronicity of built-environment radon levels in the UK. Geophysical Research Letters, 33 L05308. doi:10.1029/2005GL024950.

Darby, S., Hill, D., Auvinen, A., Barros-Dios, J.M., Baysson, H., Bochicchio, F.Darby, S. et al., 2004. Radon in homes and risk of lung cancer: collaborative analysis of individual data from 13 European case-control studies. Brit. Med. J. 330, 223-227. doi:10.1136/bmj.38308.477650.63.

Denman, A.R., 2008. Applying the ionising radiation regulations to radon in the UK workplace. Radiat. Prot. Dosim. 130, 38-42. doi:10.1093/rpd/ncn104.

Denman, A.R., Crockett, R.G.M., Groves-Kirkby, C.J., Phillips, P.S., Gillmore, G.K., Woolridge, 2007a. The value of seasonal correction factors in assessing the health risk from domestic radon: a case study in Northamptonshire, UK. Environ. Internat. 33, 34-44.

doi:10.1016/j.envint.2006.06.021.

Denman, A.R., Groves-Kirkby, N.P., Groves-Kirkby, C.J., Crockett, R.G.M., Phillips, P.S., Woolridge, A.C., 2007b. Health implications of radon distribution in living rooms and bedrooms in U.K. dwellings - A case study in Northamptonshire. Environ. Internat. 33, 999-1011. doi:10.1016/j.envint.2007.01.011.

Denman, A.R., Sinclair, J., Phillips, P.S., Crockett, R.G.M., Groves-Kirkby, C.J., 2013. The costeffectiveness of radon reduction programmes in domestic housing in England and Wales: the impact of improved radon mapping and housing trends. Env. Internat. 59, 73-85.

doi:10.1016/j.envint.2013.05.012. 
Dolejs, J., Hulka, J., 2003. The weekly measurement deviations of indoor radon concentration from the annual arithmetic mean. Radiat. Prot. Dosim. 104, 253-258.

Eaton, R., Scott, A., 1984. Understanding radon transport into houses. Radiat. Prot. Dosim. 7, 251-253,

Florea, N., Duliu, O., 2012. Eighteen years of continuous observation of radon and thoron progenies atmospheric activity. J. Environ. Radioact. 104, 14-23.

doi:10.1016/j.jenvrad.2011.10.002,

Gillmore, G., Phillips, P., Denman, A., 2005. The effects of geology and the impact of Seasonal Correction Factors on indoor radon radon levels: a case-study approach. J. Environ. Radioact. 84, 469-479. doi:10.1016/j.jenvrad.2005.05.004.

Grainger, P., Shalla, S., Preece, A., Goodfellow, S., 2000. Home radon levels and seasonal correction factors for the Isle of Man. Phys. Med. Biol. 45, 2247-2252. doi:10.1088/0031$9155 / 45 / 8 / 313$

Gray, A., Read, S., McGale, P., Darby, S., 2009. Lung cancer deaths from indoor radon and the cost-effectiveness and potential of policies to reduce them. Brit. Med. J. 338, a3110. doi:10.1136/bmj.a3110.

Groves-Kirkby, C.J., Denman, A.R., Crockett, R.G.M., Phillips, P.S., Gillmore, G.K, 2006. Identification of tidal and climatic influences within domestic radon radon time-series from Northamptonshire, UK. Sci. Tot. Environ. 367, 191-202. doi:10.1016/j.scitotenv.2005.11.019.

Groves-Kirkby, C.J., Denman, A.R., Phillips, P.S., 2009a. Seasonal variability of environmental radon gas: Lorenz Curve and Gini Coefficient as characterisation tools. J. Environ. Manage. 90, 2480-2487. doi:10.1016/j.jenvman.2009.01.003.

Groves-Kirkby, C.J., Denman, A.R., Phillips, P.S., Crockett, R.G.M., J. M. Sinclair, J.M., $2009 b$. Comparison of seasonal variability in European domestic radon measurements. Nat. Hazards Earth Syst. Sci., 10, 565-569. doi:10.5194/nhess-10-565-2010.

Gunby, J.A, Darby, S.C., Miles, J.C., Green, B.M., Cox, D.R., 1993. Factors affecting indoor radon concentrations in the United Kingdom. Health Phys. 64, 2-12.

Hubbard, L.M., Hagberg, N., 1996. Time variation of the soil gas radon concentration under and near a Swedish house. Environ. Internat. 22, S477-S482. 10.1016/s0160-4120(96)00148-1.

Ibrahimi, Z., Miles, J., 2009a. An etched track detector for short-term screening measurements of radon. J. Radiol. Prot. 29, 139-146. doi:10.1088/0952-4746/29/2/002.

Ibrahimi, Z., Miles, J., 2009b. Reply to "comment on 'an etched track detector for short-term screening measurements of radon'". J. Radiol. Prot. 29, 450-451. doi:10.1088/09524746/29/2/002.

Karpinska, M., Mnich, Z., Kapala, J., 2004. Seasonal changes in radon concentrations in buildings in the region of northeastern Poland. J. Environ. Radioact. 77, 101-109. doi:10.1016/j.jenvrad.2004.02.005.

Kobayashi, T., 2000. Concentration ratio of radon progeny in air. $10^{\text {th }}$ International Congress of the International Radiation Protection Association, Hiroshima, Japan, May 14 - 19, 2000.

Krewski, D., Lubin, J.H., Zielinski, J.M, Alavanja, M., Catalan, V.S., Field, R.W., 2005. Residential radon and risk of lung cancer: a combined analysis of 7 North American case-control studies. Epidemiology 16, 137-144. doi:10.1097/01.ede.0000152522.80261.e3.

McColl, N.P., Miles, J.C.H., Green, B.M.R., Dixon, D.W., Fey, R., Meara, J.R., Harrison, J.D, Cooper, J.R., 2010. Limitation of human exposure to radon. Documents of the Health Protection Agency. RCE-15. ISBN: 978-0-85951-669-3. 
Miles, J., 1998. Mapping radon-prone areas by lognormal modelling of house radon data. Health Phys. 74, 370-378.

Miles, J., 2001. Temporal variation of radon levels in houses and implications for radon measurement strategies. Radiat. Prot. Dosim. 93, 369-375.

Miles, J., Appleton, J., 2005. Mapping variation in radon potential both between and within geological units. J. Radiol. Prot. 25, 257-276. doi:10.1088/0952-4746/25/3/003.

Miles, J., Howarth, C., 2008. Validation scheme for laboratories making measurements of radon in dwellings: 2008 revision. HPA-RPD-047. Health Protection Agency, Didcot. ISBN .978-0-85951629-637.

Miles, J., Howarth, C., Hunter, N., 2012. Seasonal variation of radon concentrations in UK homes. J. Radiol. Prot. 32, 275-287 and 2014 corrigendum J. Radiol. Prot. 34, 493. doi:10.1088/0952$4746 / 32 / 3 / 275$.

Mose, D., Mushrush, G., Crosniak, C., 1991. Seasonal indoor radon variations related to precipitation. J. Environ. Mol. Mutagen. 17, 223-230. doi:10.1002/em.2850170402

Neznal, M., Matolin, M., Just, G., Turek, K., 2004. Short-term temporal variations of soil gas radon concentration and comparison of measurement techniques. Radiat.Prot.Dosim. 108, 55-63. doi:10.1093/rpd/nch004.

Neznal, M., Neznal, M., Smard, J., 1996. Assessment of radon potential of soils - a five year experience. Environ. Internat. 22, S819-S828. doi:10.1016/S0160-4120(96)00189-4.

O'Riordan, M.C., 1990. Human exposure to radon in homes: recommendations for the practical application of the Board's statement. Docs. NRPB 1, 17-32.

Paridaens, J., de Saint-Georges, L., Vanmarcke, H., 2005. Mitigation of a radon-rich Belgian dwelling using active sub-slab depressurisation. J. Environ. Radioact. 79, 25-37. doi:10.1016/j.jenvrad.2004.06.001.

Parkin, D. M., Darby, S., 2011. Cancers in 2010 attributable to ionising radiation in the UK. Brit. J. Cancer 105, S57-S65. doi:10.1038/bjc.2011.485.

Perrier, F., Girault, F., 2013. Harmonic response of soil radon-222 flux and concentration induced by barometric oscillations. Geophys. J. Int. 195, 945-971. doi:10.1093/gji/ggt280.

Perrier, F., Richon, P., Sabroux, J-C., 2009. Temporal variations of radon concentration in the saturated soil of Alpine grassland: The role of groundwater flow. Sci. Tot. Environ. 407, 23612371. doi:10.1016/j.jenvrad.2004.06.001.

Pinel, J., Fearn, T., Darby, S., Miles, J., 1995. Seasonal correction factors for indoor radon measurements in the United Kingdom. Radiat. Prot. Dosim. 58, 127-132.

Postendörfer, J., Butterweck, G., Reineking, A., 1994. Daily variation of the radon concentration indoors and outdoors and the influence of meteorological parameters. Health Phys. 67, 283-287.

Simpson, G.C. 1919. The twelve-hourly barometer oscillation. Q. J. R. Meteorol. Soc., 44, 1-18. doi: 10.1016/j.jenvrad.2013.04.014

Singh, M., Singh, K., Singh, S., Papp, Z., 2008. Variation of indoor radon progeny concentration and its role in dose assessment. J. Environ. Radioact. 99, 539-545.

doi:10.1016/j.jenvrad.2007.08.023.

Tapia, R., Kanevski, M., Maignan, M., Gruson, M., 2006. Comprehensive multivariate analysis of indoor radon data in Switzerland. 8th International Workshop on the Geological Aspects of Radon Risk Mapping, Prague, September 26th - 30th, 2006. 
UKCC (UK Childhood Cancer Investigators), 2000. The United Kingdom Childhood Cancer Study: objectives, materials and methods. Brit. J. Cancer 82, 1073-1102. doi:10.1054/bjoc.1999.1045.

Vasilyev, A.V., Zhukovsky, M.V. 2013. Determination of mechanisms and parameters which affect radon entry into a room. J. Environ. Radioact. 124, 185-190. doi:10.1016/j.jenvrad.2013.04.014.

Weinberg, C., Moledor, E., Umbach, D., Sandler, D., 1996. Imputation for exposure histories with gaps, under an excess relative risk model. Epidemiol. 7, 490-496.

Wilk, M., Gnanadesikan, R., 1968. Probability plotting methods for the analysis of data. Biometrika 55, 1-17.

Wrixon, A.D., Green, B.M.R., Lomas, P.R., Miles, J.C.H., Cliff, K.D., Francis, E.A. Natural radiation exposure in UK dwellings. NRPB-R190, NRPB, Chilton, 1988. 